\title{
Multi-criteria optimization for a cost-effective design of an RFID-based meat supply chain
}

\author{
Mohammed, A. \& Wang, Q.
}

\begin{abstract}
Purpose - In this paper, the authors investigated a proposed RFID (radio frequency identification)-based meat supply chain to monitor quality and safety of meat products they purchase from supermarkets. The supply chain consists of farms, abattoirs and retailers. The purpose of this work presented in this paper was to determine a cost-effective tradeoff decision obtained from a developed multi-criteria optimization model based on three objectives. These objectives include customer satisfaction in percentage of product quantity as requested by customers, product quality in numbers of meat products and the total implementation cost. Furthermore, this work was aimed at determining the number and locations of farms and abattoirs that should be established and quantities of products that need to be transported between entities of the proposed supply chain.

Design/methodology/approach - To this aim, a tri-criteria optimization model was developed. The considered criteria were used for minimizing the total implementation cost and maximizing customer satisfaction and product quality. In order to obtain Pareto solutions based on the developed model, four solution approaches were employed. Subsequently, a new decision-making algorithm was developed to select the superior solution approach in terms of values of the three criteria.

Findings - A case study was applied to examine the applicability of the developed model and the performance of the proposed solution approaches. The computational results proved the applicability of the developed model in obtaining a trade-off among the considered criteria and solving the RFID-based meat supply chain design problem.

Practical implications - The developed tri-criteria optimization model can be used by decision makers as an aid to design and optimize food supply chains.

Originality/value - This article presents a development of (i) a cost-effective optimization approach for a proposed RFID-based meat supply chain seeking a trade-off among three conflicting criteria; and (ii) a new decision making algorithm which can be used for any multi-criteria problem to select the best Pareto solution.
\end{abstract}

Keywords: Meat supply chain; Multi-criteria optimization; Customer satisfaction; Decision making algorithm.

\section{Introduction}

Meat supply chains generally constitute four different echelons which forms a network including farms, abattoirs, retailers and customers. In recent years, safety and quality of food products, which are supplied through a food supply chain network, has been one of major issues on which consumers demand more transparent information relating to food they purchase at supermarkets (Ahmed, 2008; Lever \& Miele, 2012). A study by Peattie, Peattie \& Jamal (2006) suggested that consumers often spend a considerable amount of time and effort seeking out fresh food by reading information such as expiry dates shown 
on product labels to ensure that they purchase a good quality of food products. One way to provide the prompt information on food status is to implement the RFID technology. In the past decade, implementation of RFID technology has been gaining an ever-increasing popularity as it enhances traceability of safety and quality of food products (Chrysochou et al., 2009; Manos \& Manikas, 2010; Zailani et al., 2010).

Through a literature review, little research works were found for investigating the RFIDenabled supply chains seeking a compromised solution between the benefits of the RFID implementation in supply chains and its need for additional costs in relevance to the supply chain network design. In this paper, the authors examined a proposed RFID-based threeechelon meat supply chain seeking a compromised solution based on objective functions relating to the total implementation cost, customer satisfaction in percentage of satisfying customers' demand in product quantity, and product quality in numbers of meat products. To this aim, a tri-criteria mixed integer linear programming model was developed. The work also includes the determination of (i) number and locations of farms and abattoirs that should be established and (ii) quantities of livestock transported from farms to abattoirs and meat products transported from abattoirs to retailers. By solving the tri-criteria optimization problem, four solution approaches were investigated. These are compromise programming, goal programming, weighted Tchebycheff and utility function. A developed decision making algorithm was employed to select the superior solution approach based on computational results values. This approach can be used as a reference for decision makers to obtain a cost-effective design of food supply chains.

\section{Prior studies}

Multi-objective optimization refers to an optimization of multiple decision making objectives concurrently. These objectives are possibly conflicting and competing. According to a thesis work of Almaraz, 2014, in a multi-objective problem, it is impossible to obtain a single ideal solution but a trade-off among a number of objectives, since there is a contradictory among the objectives. Pareto optimal solutions are obtained based on multiple conflicting criteria. Multi-criteria optimization models were applied into supply chain network designs for solving production-distribution planning problems (Gen \& Heng, 1997; Deb, 2001; Shen \& Daskin, 2005; Shen \& Daskin, 2005; Sabri \& Beamon, 2009; Pandu, 2009; Hu \& Li, 2009;). These problems can be strategic in such as the facility location-allocation problem or tactical in such as the flow of product quantities. Costs or profits are among one of other issues that may need to be considered (Jayaraman and Pirkul 2001, Syam 2002 and Syarif, Yun, and Gen 2002, Jayaraman and Ross 2003, Yan, Yu, and Cheng 2003). Altiparmak, Gen, Lin, and Paksoy (2006) proposed a genetic algorithm focusing on minimization of inbound and outbound distribution costs and maximization of customer services in terms of delivery time and capacity of distribution centers. Selim, Araz \& Ozkarahan (2008) presented a multi-criteria optimization model to cope with a production-distribution planning problem in a supply chain. Fuzzy goal programming was 
used to incorporate decision maker's imprecise goal levels for each objective. Ferrio and Wassick (2008) formulated a mixed integer linear programming model for configuring and optimizing the design of a multi-product chemical supply chain network which consists of production sites, arbitrary numbers of distribution centers, and customers. Schütz, Tomasgard and Ahmed (2008) formulated a decision support system using a two-stage stochastic program with respect to minimizing costs of investment and operations of a supply chain. Tuzkaya and Onut (2009) studied a three-level supply chain including supplier, warehouses, and manufacturers seeking the best distribution plan of products. Li et al. (2009) developed a multi-objective optimization model to configure distribution center locations; the considered objectives were minimization of the transportation cost, transportation and production carbon emissions. Chang (2010) presented a single-objective mathematical model to optimize a multiple level supply chain network design encompassing suppliers, factories, distribution centers and retailers. The considered objective was to minimize the total cost including purchasing and transportation cost of raw materials and products, manufacturing cost of products in factories, and storage cost of products in distribution centers. Alumur et al. (2012) proposed a profit maximization modeling framework for a reverse logistics network design problem. The same method was also used by Sadjady and Davoudpour (2012) to tackle a two-level supply chain network design problem. The problem was formulated as a mono-criteria optimization model to minimize total cost, which include costs in transportation, lead-times and inventory for products and opening and operating costs for facilities. Pourrousta et al. (2012) developed a multi-objective model to minimize total cost and delivery time of products in a multiechelon supply chain network. Liu and Papageorgiou (2014) proposed a multi-criteria optimization model for tackling a production-distribution and capacity planning problem in a supply chain using the $\varepsilon$-constraints and Lexicographic min-max methods.

\section{Mathematical formulation}

109

In this study, a meat supply chain comprises three echelons: farms, abattoirs and retailers, was studied. In this chain, farms supply livestock to abattoirs where slaughtered livestock as packed meat products are transported to retailers. The RFID technology was proposed for tracing safety and quality of meat products during the transportation process from farms to abattoirs and from abattoirs to retailers (Mohammed \& Wang, 2015). Fig. 1 depicts the structure illustration of the investigated meat supply chain. 

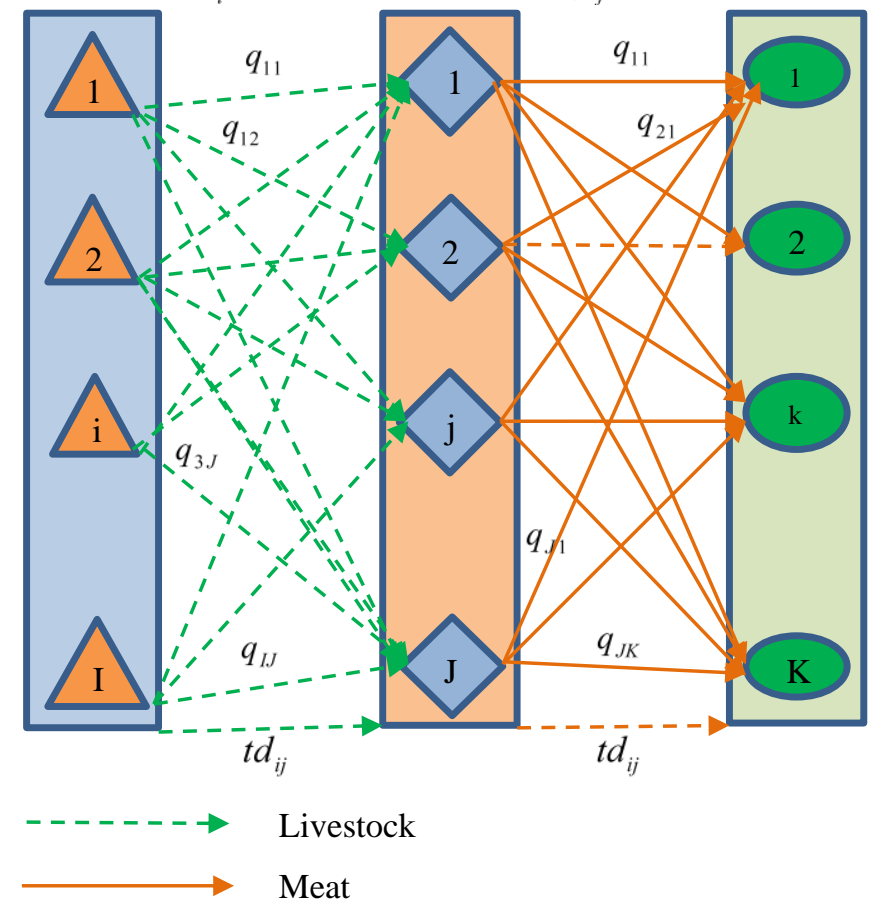

Fig. 1. The structure of the meat supply chain network.

131 To formulate the tri-criteria model, the following indices, parameters and decision variables are presented:

133 Indices

$134 I$ index used for a potential location of farm $i, 1 \leq i \leq I$

$135 J$ index used for a potential location of abattoir $j, 1 \leq j \leq J$

$136 K$ index for a fixed location of retailer $k, 1 \leq k \leq K$

Cost parameters:

139

$C_{i}^{\alpha} \quad$ cost (£) of RFID equipment and implementation required for farm $i$

$140 C_{j}^{\beta} \quad$ cost (£) of RFID equipment and implementation required for abattoir $j$

$141 C_{i}^{t} \quad$ RFID tag cost (£) for each item at farm $i$

$142 \quad C_{j}^{t} \quad$ RFID tag cost (£) for each item at abattoir $j$

$143 T C_{i j}$ unit transportation cost (£) per mile from farm $i$ to abattoir $j$

$144 T C_{j k}$ unit transportation cost $(\mathfrak{E})$ per mile from abattoir $j$ to retailer $k$

$145 L C_{i}^{\alpha}$ unit labor cost (£) per hour at farm $i$

$146 L C_{j}^{\beta}$ unit labor cost (£) per hour at abattoir $j$ 
148 Parameters of capacity, demand and transportation distance:

$149 S_{\mathrm{i}}^{\alpha}$ maximum supply capacity (units) of farm $i$

$150 S_{\mathrm{j}}^{\beta} \quad$ maximum supply capacity (units) of abattoir $j$

$151 W_{v}$ transportation capacity (units) per vehicle $(v)$

$152 \mathrm{D}_{\mathrm{j}}^{\beta}$ minimum demand (in units) of abattoir $j$

$153 \mathrm{D}_{\mathrm{k}}^{\delta}$ minimum demand (in units) of retailer $k$

$154 d_{i j}$ travel distance (mile) from farm $i$ to abattoir $j$

$155 d_{j k}^{n}$ travel distance (mile) from abattoir $j$ to retailer $k$

157 Labor parameters:

$158 R_{i}^{l \alpha}$ working rate (items) per laborer $(l)$ at farm $i$

$159 R_{j}^{l \beta}$ working rate (items) per laborer $(l)$ at abattoir $j$

$160 N_{i}^{h \alpha}$ minimum required number of working hours $(h)$ for laborer $l$ at farm $i$

$161 N_{j}^{h \beta}$ minimum required number of working hours $(h)$ for laborer $l$ at abattoir $j$

162

163

164

165

166

167

168

169

170

171

172

173

174

175

176

177

178

179
Other parameters

$Q_{i j}$ healthiness percentage of livestock transported from farm $i$ to abattoir $j$

$F_{j k}$ freshness percentage of meat products pieces transported from abattoir $j$ to retailer $k$

Decision variables:

$q_{\mathrm{ij}} \quad$ quantity of units transported from farm $i$ to abattoir $j$

$q_{\mathrm{jk}} \quad$ quantity of units transported from abattoir $j$ to retailer $k$

$x_{i}^{\alpha} \quad$ number of required laborers at farm $i$

$x_{j}^{\beta} \quad$ number of required laborers at abattoir $j$

Non-negative and binary decision variables:

$$
\begin{aligned}
y_{\mathrm{i}}^{\alpha} & =\left\{\begin{array}{l}
1: \text { if farm } i \text { is open } \\
0: \text { otherwise }
\end{array}\right. \\
\mathrm{y}_{\mathrm{j}}^{\beta} & =\left\{\begin{array}{l}
1: \text { if abattoir } j \text { is open } \\
0: \text { otherwise }
\end{array}\right.
\end{aligned}
$$

The criteria functions are formulated as follows: 
180 The minimum total cost $F_{1}=$ costs of RFID equipment and implementation + RFID tag 181 cost for each item + transportations costs - labor costs saved after the RFID 182 implementation, i.e.,

$$
\begin{aligned}
& \operatorname{Min} F_{1}=\sum_{i \in I} C_{i}^{\alpha} y_{i}^{\alpha}+\sum_{j \in J} C_{j}^{\beta} y_{j}^{\beta}+\sum_{i \in I} C_{i}^{t \alpha} q_{i j}+\sum_{j \in J} C_{j}^{t \beta} q_{j k} \\
& +\sum_{i \in I} \sum_{j \in J} T C_{i j}\left[q_{i j} / W_{v}\right\rceil d_{i j}+\sum_{j \in J} \sum_{k \in K} T C_{j k}\left\lceil q_{j k} / W_{v}\right\rceil d_{j k} \\
& -\sum_{i \in I} L C_{i}^{\alpha} x_{i}^{\alpha} N_{i}^{h \alpha}-\sum_{j \in I} L C_{j}^{\beta} x_{i}^{\beta} N_{j}^{h \beta}
\end{aligned}
$$

183 The maximum customer satisfaction $F_{2}=$ the fulfilment of demand in percentage of product 184 quantity as requested by customers, i.e.,

$$
\operatorname{Max} F_{2}=\sum_{k=1}^{K}\left(\sum_{j=1}^{J} q_{i j} / D_{k}^{\delta}\right)
$$

185 Maximum product quality $F_{3}=$ healthiness of livestock transported from farms to abattoirs 186 + freshness of meat pieces transported from abattoirs to retailers, i.e.,

$$
\operatorname{Max} F_{3}=\sum_{i=1}^{I} Q_{i j} y_{i}^{\alpha}+\sum_{j=1}^{J} F_{j k} y_{j}^{\beta}
$$

187 Several constraints are grouped in different categories as follows:

188 Capacity constraints: show the capacity constraints of farms and abattoirs.

$$
\begin{array}{ll}
\sum_{i \in I} q_{i j} \leq S_{i}^{\alpha} \mathrm{y}_{i}^{\alpha} & \forall \mathrm{j} \in \mathrm{J} \\
\sum_{j \in J} q_{\mathrm{jk}} \leq S_{\mathrm{j}}^{\beta} \mathrm{y}_{\mathrm{j}}^{\beta} & \forall \mathrm{k} \in K
\end{array}
$$

189 Demand constraints: ensure that the demands in quantity of products of all abattoirs and 190 retailers are satisfied.

$$
\begin{array}{ll}
\sum_{\mathrm{i} \in \mathrm{I}} q_{\mathrm{ij}} \geq \mathrm{D}_{\mathrm{j}}^{\beta} & \forall \mathrm{j} \in \mathrm{J} \\
\sum_{\mathrm{j} \in \mathrm{J}} q_{\mathrm{jk}} \geq \mathrm{D}_{\mathrm{k}}^{\delta} & \forall \mathrm{k} \in \mathrm{K} \\
\mathrm{D}_{\mathrm{j}}^{\beta} \geq \sum_{\mathrm{k} \in \mathrm{K}} q_{\mathrm{jk}} & \forall \mathrm{j} \in \mathrm{J}
\end{array}
$$

192 Working rate constraints: determine the required number of laborers at farms and abattoirs. 


$$
\begin{array}{ll}
\sum_{j \in J} q_{i j} \leq x_{i}^{\alpha} \mathrm{R}_{i}^{1 \alpha} & \forall \mathrm{i} \in I \\
\sum_{k \in K} q_{\mathrm{jk}} \leq x_{\mathrm{j}}^{\beta} \mathrm{R}_{\mathrm{j}}^{1 \beta} & \forall \mathrm{j} \in J
\end{array}
$$

193

194

Restriction constraints: restrict the decision variables to binary and non-negative.

$$
\begin{aligned}
& q_{i j}, q_{j k} \geq 0, \forall i, j, k ; \\
& y_{i}^{\alpha}, y_{j}^{\beta} \in\{0,1\}, \forall i, j ;
\end{aligned}
$$

Finally, $0.75 \leq Q_{i j} \leq 1$ and $0.75 \leq F_{j k} \leq 1$ constraints, which limit the healthiness percentage $(Q)$ and the freshness percentage $(F)$ to be between 0.75 and 1 (based on decision makers' preferences).

\section{Multi-criteria optimization methodology}

Multi-criteria optimization involves the simultaneous optimization of a number of decision making criteria which are conflicting and often competing. In order to solve this type of optimization problem, researchers deal with a set of solutions known as Pareto optimal solutions. Nevertheless, it can be a case that none of these Pareto solutions is better than the others considering all the criteria. Different approaches can be aided in solving such a problem. In this study, four different solution approaches were investigated aimed to obtain four sets of Pareto solutions to be selected as the best one in terms of solution quality

\subsection{Compromise programming approach}

The compromise programming approach is its ability to achieve efficient points in a nonconvex Pareto curve (Chankong \& Haimes, 1983). This method based on optimizing one criterion function and shifting the other to the constraint set to be restricted to an assigned value $(\varepsilon)$. The equivalent solution formula $F$ is presented as follows.

$$
\begin{aligned}
& \operatorname{Min} F=\sum_{i \in I} C_{i}^{\alpha} y_{i}^{\alpha}+\sum_{j \in J} C_{j}^{\beta} y_{j}^{\beta}+\sum_{i \in I} C_{i}^{t \alpha} q_{i j} \\
& +\sum_{j \in J} C_{j}^{t \beta} q_{j k}+\sum_{i \in I} \sum_{j \in J} T C_{i j}\left\lceil q_{i j} / W_{v}\right\rceil d_{i j}+\sum_{j \in J} \sum_{k \in K} T C_{j k}\left\lceil q_{j k} / W_{v}\right\rceil d_{j k} \\
& -\sum_{i \in I} L C_{i}^{\alpha} x_{i}^{\alpha} N_{i}^{h \alpha}-\sum_{j \in I} L C_{j}^{\beta} x_{i}^{\beta} N_{j}^{h \beta}
\end{aligned}
$$

Additional constraints: 


$$
\begin{aligned}
& \sum_{k=1}^{K}\left(\sum_{j=1}^{J} q_{i j} / D_{k}^{\delta}\right) \geq \varepsilon_{1} \\
& {\left[\sum_{k=1}^{K}\left(\sum_{j=1}^{J} q_{i j} / D_{k}^{\delta}\right)\right]^{\min } \leq \varepsilon_{1} \leq\left[\sum_{k=1}^{K}\left(\sum_{j=1}^{J} q_{i j} / D_{k}^{\delta}\right]\right]^{\max }} \\
& \sum_{i=1}^{I} Q_{i j} y_{i}^{\alpha}+\sum_{j=1}^{J} F_{j k} y_{j}^{\beta} \geq \varepsilon_{2} \\
& {\left[\sum_{i=1}^{I} Q_{i j} y_{i}^{\alpha}+\sum_{j=1}^{J} F_{j k} y_{j}^{\beta}\right]^{\min } \leq \varepsilon_{2} \leq\left[\sum_{i=1}^{I} Q_{i j} y_{i}^{\alpha}+\sum_{j=1}^{J} F_{j k} y_{j}^{\beta}\right]^{\max }}
\end{aligned}
$$

217 In this paper, criterion function one is selected to be optimized based on Eq.13 and shifting 218 criterion function two and three to be constraints (Eq. 14 and 16 respectively); An increase 219 to the $\varepsilon$ value (Eq.15 and 17) yields Pareto solutions.

\section{4.2. Goal programming approach}

221 The purpose of the goal programming approach is to find a solution that minimizes 222 undesirable deviations between the objective functions and their corresponding goals 223 (Charnes, Cooper \& Ferguson, 1955; Colapinto, Jayaraman \& Marsiglio, 2015). The 224 solution functions are expressed as follows:

Min F

$$
\frac{\varsigma^{1}}{\mathrm{G}^{1}} \leq F
$$

$$
\begin{aligned}
& \frac{v^{2}}{G^{2}} \leq F \\
& \frac{v^{3}}{G^{3}} \leq F
\end{aligned}
$$

The equivalent criteria functions are expressed as follows. 


$$
\begin{aligned}
& \operatorname{Min} F_{1}=\sum_{i \in I} C_{i}^{\alpha} y_{i}^{\alpha}+\sum_{j \in J} C_{j}^{\beta} y_{j}^{\beta}+\sum_{i \in I} C_{i}^{t \alpha} q_{i j}+\sum_{j \in J} C_{j}^{t \beta} q_{j k} \\
& +\sum_{i \in I} \sum_{j \in J} T C_{i j}\left\lceil q_{i j} / W_{v}\right\rceil d_{i j} \\
& +\sum_{j \in J} \sum_{k \in K} T C_{j k}\left[q_{j k} / W_{v}\right] d_{j k}-\sum_{i \in I} L C_{i}^{\alpha} x_{i}^{\alpha} N_{i}^{h \alpha}-\sum_{j \in I} L C_{j}^{\beta} x_{i}^{\beta} N_{j}^{h \beta} \\
& +\varsigma^{1}-v^{1}=\mathrm{G}^{1} \\
& \operatorname{Max}_{2}=\sum_{k=1}^{K}\left(\sum_{j=1}^{J} q_{i j} / D_{k}^{\delta}\right)+\varsigma^{2}-v^{2}=\mathrm{G}^{2} \\
& \operatorname{Max}_{3}=\sum_{i=1}^{I} Q_{i j} y_{i}^{\alpha}+\sum_{j=1}^{J} F_{j k} y_{j}^{\beta}+\varsigma^{3}-v^{3}=\mathrm{G}^{3}
\end{aligned}
$$

227 Where

$$
\begin{array}{ll}
\mathrm{G}^{1} & \text { goal of the criterion } 1 \\
\mathrm{G}^{2} & \text { goal of the criterion } 2 \\
\mathrm{G}^{3} & \text { goal of the criterion } 3 \\
\varsigma^{1} & \text { negative deviation variable of the criterion } 1 \\
\varsigma^{2} & \text { negative deviation variable of the criterion } 2 \\
\varsigma^{3} & \text { negative deviation variable of the criterion } 3 \\
v^{1} & \text { positive deviation variable of the criterion } 1 \\
v^{2} & \text { positive deviation variable of the criterion } 2 \\
v^{3} & \text { positive deviation variable of the criterion } 3
\end{array}
$$

228 Subject to an additional non-negativity restriction:

$$
\varsigma, v \geq 0
$$

\subsection{Weighted Tchebycheff approach}

231 With this approach, the multi-objective possibilistic model can be transformed into a 232 single-objective model $F$. The purpose of the single-objective model is to minimize the 233 distance between the ideal objective vector $F^{*}$ and the feasible objective surface 234 (Miettinen, 1998). The solution approach function $F$ can be formulated as follows: 235

$$
\operatorname{Min} F=\left(\sum_{n=1}^{3} l_{n}\left|F_{n}-F^{*}\right|^{p}\right)^{\frac{1}{p}}
$$


237 Subject to constraints 4-12. Noticeably, the values of objective functions vary depending 238 on the value of $p$. Usually, $p$ is set as 1 or 2 . But, other values of $p$ can also be used. In this 239 case study, $p$ is set as 1.

240

241

242

243

244

245

246

247

248

249

250

251

252

253

254

255

256

257

258

259

260

261

262

263

264

265

266

267

\subsection{Utility function approach}

In the utility function approach, the effectiveness utility of each Pareto solution is determined by summing the scaled criteria functions. The scalar value $\lambda$ for each criterion is determined by decision maker according to the importance for each criterion (Stoll, 1999). In this work, the criterion function (or utility function) $U$ is expressed as follows:

$$
U\left(F_{1}, F_{2}\right)=\left\{\sum_{n=1}^{2} \lambda_{n} F_{n} \mid \lambda_{n}<1, \sum_{n=1}^{2} \lambda_{n}=1\right\}
$$

\subsection{Decision making algorithm}

In this paper, the selection algorithm is based onto two stages; in the first stage the best trade-off solution is selected for each set of solutions. Selecting the superior approach is determined in the subsequent stage. The next two sub-sections present the two stages respectively.

\subsubsection{Global criterion approach}

There are several methods for selecting the most suitable solution in a multi-objective problem. In this case, the global criterion method was used for determining the best solution by minimizing the distance to the ideal objective value $F_{n}^{*}$ (Pandu, 2009). The decision making formula is expressed as follows:

$$
\operatorname{Min} F=\left(\sum_{n=1}^{3}\left|F_{n}-F_{n}^{*}\right|^{\rho}\right)^{1 / \rho} ; 1 \leq \rho \leq \infty
$$

In this approach, the solution with the minimum distance is selected as a best solution. Generally, $\rho$ is 1 ; However, other values of $\rho$ also can be used.

\subsubsection{The developed approach}

The idea of the developed approach for selecting the best approach is based on selecting the solution approach that is closest to the ideal solution. In this approach, $S^{*}$ represents the average superiority value for each approach; (i) determine the average mean value for the three criterion functions, (ii) sum the three average mean values, and (iii) select the approach with the lowest superiority value. The selection formula is presented as follows: 


$$
S^{*}=\sum_{n=1}^{3} \frac{F_{n}}{F_{n}^{*}}
$$

268 Where $F_{i}^{*}$ is the ideal value for each criterion. This value is determined by optimizing the

269 criteria functions individually.

\section{5. Application and comparison: South East London as a case study}

271 A case study is presented to demonstrate the applicability of the developed tri-criteria 272 model and compare the performance of the proposed solution approaches in terms of the 273 criteria values. In the case study, the South-East area of London encompasses 4 farms (I), 2747 retailers $(K)$ and 4 abattoir $(J)$ suppliers. Table 1 shows the collected data which are 275 chosen in a defined range (based on assumptions). Data, which are related to locations of 276 farms, abattoirs and retailers, were collected from the Meat Committee in the UK (HMC, 277 2015). The transportation distances between supply chain facilities were estimated using 278 Google-Maps. The demand reported in Table 1 is the total demand over a one-year period. 279 The prices of RFID equipment and its implementation were estimated based on the 280 marketing prices.

281

282

Table 1. Parameters used for the case study

\begin{tabular}{|c|c|c|c|}
\hline$I=4$ & $C_{j}^{\beta}=1.1 \mathrm{~K}-8 \mathrm{~K}(£)$ & $D_{k}^{\gamma}=100-800$ & $d_{i j}=23-400$ \\
\hline$J=7$ & $T C_{j k}=20(£)$ & $d_{j k}=110-162$ & $L C_{i}^{\alpha}=6.5(£)$ \\
\hline$K=4$ & $S_{i}^{\alpha}=2.5 \mathrm{~K}-4.4 \mathrm{~K}$ & $W_{v}=100$ & $L C_{j}^{\beta}=6.5(\mathfrak{})$ \\
\hline$C_{i}^{\alpha}=4.4 \mathrm{~K}-8.8 \mathrm{~K}(\mathfrak{f})$ & $S_{j}^{\beta}=1.2 \mathrm{~K}-1.8 \mathrm{~K}$ & $R_{i}^{1 \alpha}=50$ & $F_{j k}=0.75-1$ \\
\hline$T C_{i j}=20(£)$ & $D_{j}^{\beta}=800-1.3 \mathrm{~K}$ & $R_{j}^{1 \beta}=50$ & $Q_{i j}=0.75-1$ \\
\hline$C_{i}^{t}=0.15(£)$ & & $C_{j}^{t}=0.15(£)$ & \\
\hline
\end{tabular}

286 The tri-criteria optimization problem described in Section 3 was investigated using four 287 different approaches. This was carried out using the LINGO $^{11}$ software on a computer with 288 corei5-CPU 2.60 GHz, RAM 4.00 GB. 
Table 2 elucidates the values obtained using equation 1-3, respectively. Each value was optimized based on each criterion for obtaining the ideal solution. As shown in Table 2, the total cost can be minimized to $£ 194,180$ based on the criterion function one, while in this solution the criterion function two and three worsen to $75 \%$ and 8,885 items of meat products respectively. On the antithesis, if the second criterion function $F_{2}$ was only considered, customer satisfaction would increase to $100 \%$. However, the total cost increases to $£ 491,000$. Finally, considering the third criterion $F_{3}$ individually, the objective of product quality, which increases to 13,099 items of meat product leading to an increase in the total cost of $£ 481,390$ and customer satisfaction of $99 \%$. In this situation, the contradictory is manifested between these three criteria functions. However, moving toward an enhancement in customer satisfaction and product quality in supply chains requires significantly higher cost investment.

\section{Table 2. The values of the three criteria obtained by the individual optimization.}

\begin{tabular}{lccc}
\hline $\begin{array}{l}\text { Criterion } \\
\text { function }\end{array}$ & $\begin{array}{c}\operatorname{Min} \boldsymbol{F}_{\boldsymbol{1}} \\
(\mathfrak{})\end{array}$ & $\begin{array}{c}\operatorname{Max} \boldsymbol{F}_{\mathbf{2}} \\
(\boldsymbol{\%})\end{array}$ & $\begin{array}{l}\operatorname{Max} \boldsymbol{F}_{\mathbf{3}} \\
(\mathbf{I t e m s})\end{array}$ \\
\hline $\boldsymbol{F}_{\boldsymbol{1}}$ & 194180 & 0.75 & 8885 \\
$\boldsymbol{F}_{\boldsymbol{2}}$ & 491000 & 1 & 13099 \\
$\boldsymbol{F}_{\mathbf{3}}$ & 481390 & 0.99 & 13099 \\
\hline
\end{tabular}

As discussed above, it can be easily noticed that there is no solution which is optimal as it is impossible to obtain an optimal solution towards the three criteria at a time. To this aim, four solution approaches were employed for seeking the Pareto sets derived from cooptimizing the three contradicting criteria by minimizing total cost $F_{1}$, maximizing customer satisfaction $F_{2}$ and maximizing product quality $F_{3}$.

Pareto optimal solutions can be obtained using: (i) the compromise programming approach by altering the incremental epsilon value of 526 between 8,885 to 13,099 for criterion two (Eq.15) and of $\mathbf{0 . 0 2 5}$ between 0.75 to 1 for criterion three (Eq.17); (ii) the goal programming approach by assigning eight different goals for the three criteria ; (iii) the weighted Tchebycheff approach using the ideal values of the three criteria functions illustrated in Table 2_were given as ideal values $F_{1}^{*}, F_{2}^{*}, F_{3}^{*}$ for the solution function $F$ using Eq.26; and (iv) the utility function approach using different scalar values $\lambda$.

Table 3 shows four sets of Pareto optimal solutions which were obtained using the four solution approaches. These solutions also include numbers of farms and abattoirs that should be established. Shown in Table 3, the third column shows the values of the first 
320 criterion function $\left(F_{1}\right)$, obtained values of the second and third criterion functions ( $F_{2}$ and $\left.321 F_{3}\right)$ in terms of percentage and items are presented in the fourth and fifth columns, 322 respectively. The last two columns (right-end) correspond to the number of farms and 323 abattoirs that should be established.

324 Table 3. Pareto solutions obtained by using four different approaches.

\begin{tabular}{|c|c|c|c|c|c|c|}
\hline Solution approach & $\#$ & $\begin{array}{c}\operatorname{Min}\left(F_{2}\right) \\
(\mathfrak{f})\end{array}$ & $\begin{array}{c}\operatorname{Max}\left(F_{2}\right) \\
(\%)\end{array}$ & $\begin{array}{c}\operatorname{Max}\left(F_{3}\right) \\
\text { (items) }\end{array}$ & Open farms & Open abattoirs \\
\hline \multirow[t]{8}{*}{ Compromise programming } & 1 & 194180 & 0.75 & 8885 & 1001 & 010101 \\
\hline & 2 & 223257 & 0.776 & 9411 & 1011 & 0101 \\
\hline & 3 & 248214 & 0.8 & 9937 & 1011 & 0101 \\
\hline & 4 & 273171 & 0.826 & 10473 & 0011 & 0101 \\
\hline & 5 & 300475 & 0.85 & 10989 & 1011 & 1011 \\
\hline & 6 & 345228 & 0.91 & 11515 & 1111 & 1101 \\
\hline & 7 & 382940 & 0.95 & 12041 & 1111 & 1011 \\
\hline & 8 & 468475 & 1 & 13099 & 1111 & 0110 \\
\hline \multirow[t]{8}{*}{ Goal programming } & 1 & 221655 & 0.75 & 8885 & 1111 & 1111 \\
\hline & 2 & 228705 & 0.78 & 8913 & 0111 & 1110 \\
\hline & 3 & 288810 & 0.79 & 9912 & 1001 & 0101 \\
\hline & 4 & 237050 & 0.82 & 10311 & 1111 & 1111 \\
\hline & 5 & 279835 & 0.86 & 10586 & 1001 & 1011 \\
\hline & 6 & 336480 & 0.88 & 10642 & 1111 & 1111 \\
\hline & 7 & 4724750 & 0.9 & 11313 & 1111 & 1101 \\
\hline & 8 & 5391300 & 0.95 & 12141 & 0011 & 0110 \\
\hline \multirow{8}{*}{ Weighted Tchebycheff } & 1 & 194180 & 0.75 & 8885 & 1001 & 010101 \\
\hline & 2 & 194180 & 0.75 & 8885 & 1001 & 0101 \\
\hline & 3 & 249231 & 0.78 & 8920 & 1011 & 1111 \\
\hline & 4 & 288557 & 0.8 & 9808 & 1111 & 1111 \\
\hline & 5 & 338858 & 0.85 & 10414 & 1111 & 1111 \\
\hline & 6 & 422451 & 0.91 & 11094 & 1111 & 1101 \\
\hline & 7 & 539128 & 0.96 & 12376 & 1111 & 1111 \\
\hline & 8 & 580471 & 0.99 & 13029 & 1001 & 0101 \\
\hline \multirow[t]{8}{*}{ Utility function } & 1 & 194180 & 0.75 & 8885 & 1001 & 0101 \\
\hline & 2 & 194180 & 0.75 & 8885 & 1001 & 0101 \\
\hline & 3 & 194180 & 0.77 & 9411 & 0011 & 0101 \\
\hline & 4 & 194180 & 0.815 & 10162 & 1011 & 1011 \\
\hline & 5 & 253475 & 0.85 & 10876 & 1111 & 1101 \\
\hline & 6 & 355336 & 0.9 & 11444 & 1111 & 1011 \\
\hline & 7 & 392720 & 0.94 & 12131 & 1111 & 01110 \\
\hline & 8 & 475660 & 0.99 & 13032 & 1111 & 01111 \\
\hline
\end{tabular}

325 For instance, solution number 4 was obtained using the compromise programming 326 approach by assigning $\varepsilon_{1}=0.825$ and $\varepsilon_{2}=10,470$; accordingly, it gives the minimum total 327 cost of $£ 273,171$, the maximum customer satisfaction of $82.6 \%$ and the maximum product 328 quality of 10,473 items of meat products. This solution also includes an establishment of

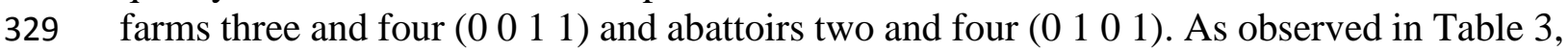
330 Pareto optimal solutions cannot be obtained according to one criterion without worsening 331 its performance in other criteria. 
333 To design the meat supply chain network, decision makers often need to find a solution 334 based on a number of alternative possibilities using a decision making approach. Fig. 2 335 illustrates Pareto fronts based on optimizing the three criteria using four solution 336 approaches.

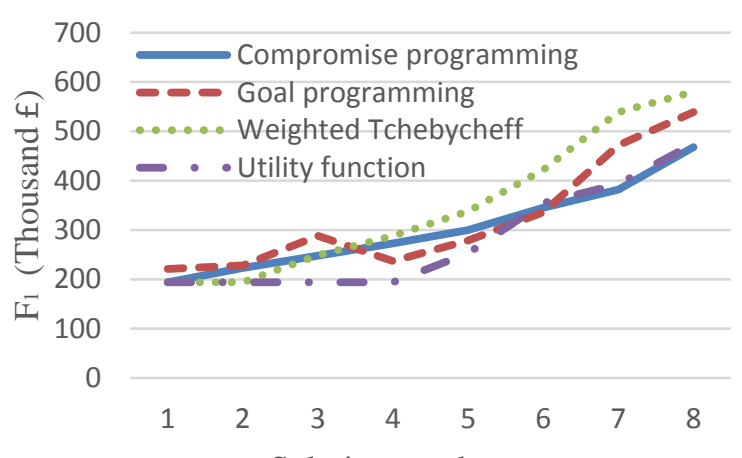

Solution number

(a) $F_{1}$

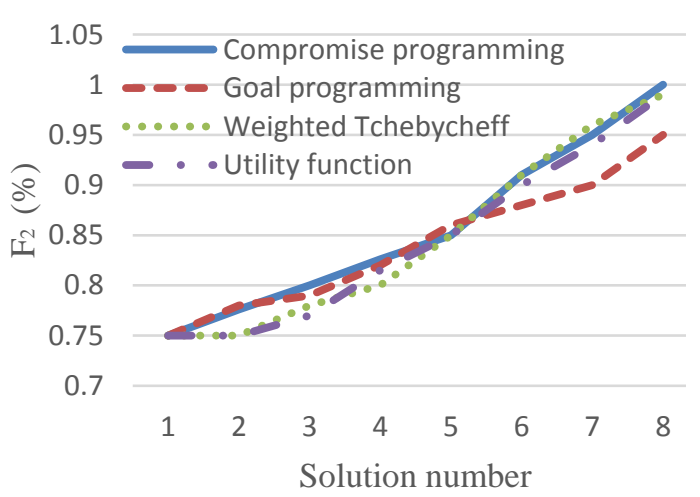

(b) $\mathrm{F}_{2}$

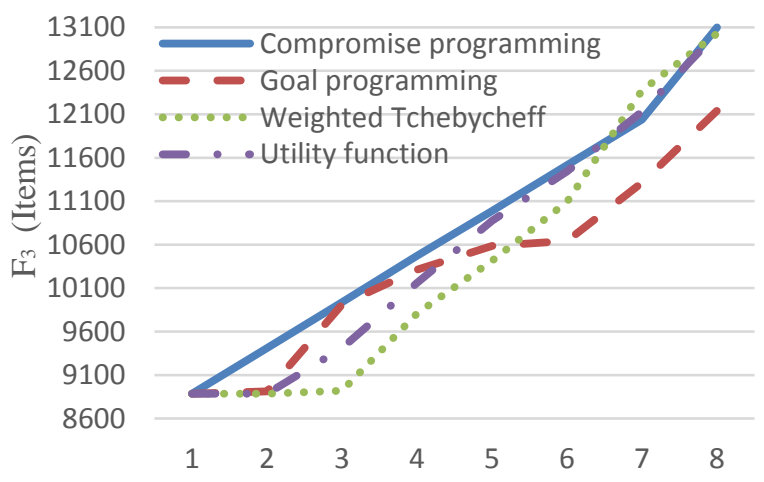

Solution number

(c) $\mathrm{F}_{3}$

351 Fig. 2 also shows the small difference in obtained criteria values in terms of minimum total cost, maximum customer satisfaction and maximum product quality using the four different approaches. This leads to the difficulty in selection of the best solution. Hence, a decision making algorithm (described in sub-section 4.5.) was used. At the first stage-the global criterion approach was employed to select the best Pareto solution for each set of solutions. In this case, Pareto solutions number 3, 2, 3 and 5 (shown in Table 3) were determined as the best solutions using the four different solution approaches as described in section 4, respectively. These solutions were achieved with the minimum distances to their ideal criteria values; the values of these distances are 1.69, 1.63, 1.741 and 1.749, respectively. The developed selection technique was then applied to select the superior approach using Eq.29. Accordingly, the obtained superiority values for the compromise 
programming approach is 2.568 , the goal programming approach is 2.637 , weighted Tchebycheff approach is 2.743 and the utility function approach is 2.97. It apparently shows that the superiority of the compromise programming approach to tackles the considered tri-criteria problem as it gives the lowest value of 2.568. Its solution (number 3 in Table 3) was obtained by assigning $\varepsilon_{1}=0.825$ and $\varepsilon_{2}=9,937$. Fig. 3 illustrates the optimal meat supply chain network design based on the determined solution.
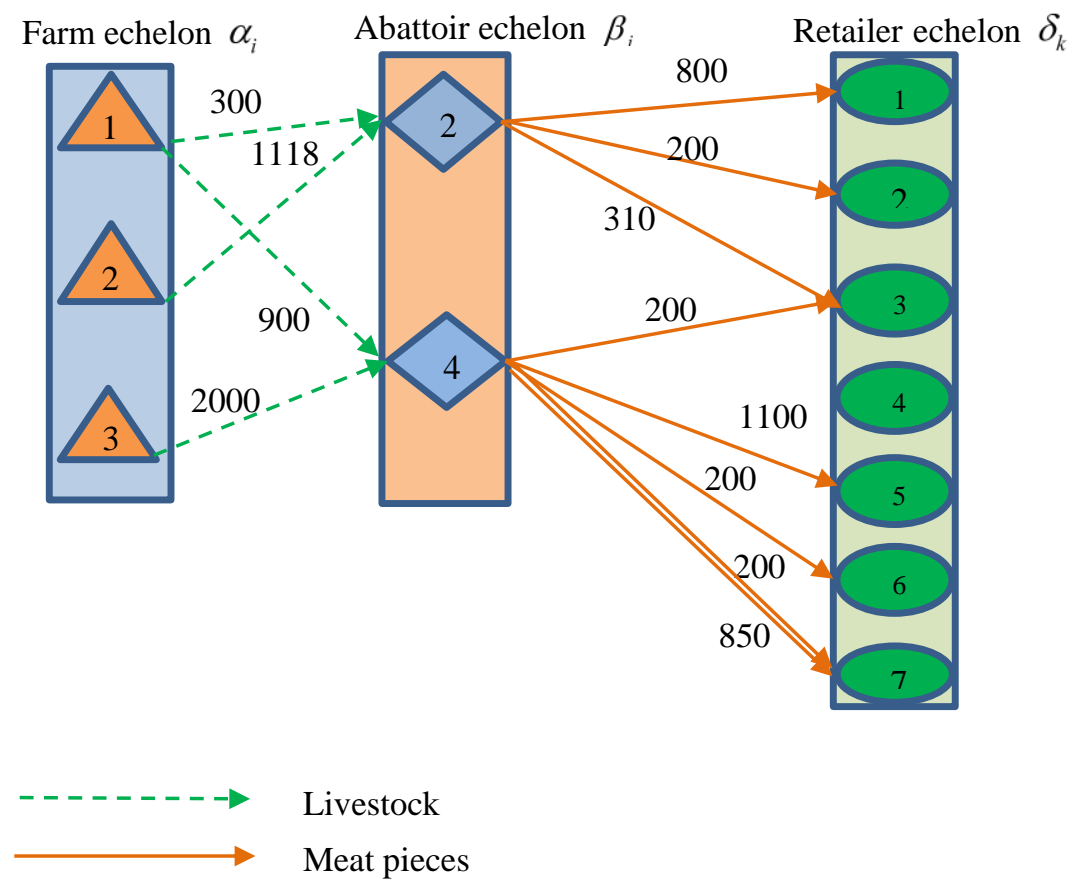

Fig. 3. The optimal meat supply chain network design.

Subsequently, three farms located in Warwickshire, Leicestershire, and the Yorkshire are determined to be established and two abattoirs located in Birmingham and Warrick. For the selected solution, the minimum total cost is $£ 248,214$, the maximum customer satisfaction is $80 \%$ and the maximum product quality is 9,937 items of meat products. The distribution plan of products was also determined; 900 livestock are to be transported from farm one (located in Warwickshire) to abattoir four (located in Warrick) and 800 items of meat products are to be transported from abattoir two (located in Birmingham) to retailer one.

\section{Conclusion}

In this paper, a multi-criteria mixed integer linear programming model was developed for solving an issue of a three-echelon RFID-based meat supply chain design based on three criteria: total cost of implementation, customer satisfaction (\%) in a fulfillment of the demand in product quantities, and product quality in numbers of meat product. To reveal 
A numerical case study was studied for examining the applicability of the developed model using four different solution approaches. Moreover, a decision making algorithm was developed to select the best solution approach. It proved the superiority of the compromise programming approach. This study shows that the developed tri-criteria optimization model can be useful for obtaining a compromised solution between economic costs and customer satisfaction of the proposed RFID-enabled meat supply chain.

An interesting research avenue derived from this work is recommended as follows:

1. Developing a fuzzy tri-criteria programming model to cope with the uncertainty in costs, demands, healthiness percentage of livestock and freshness percentage of meat products.

2. Solving the multi-criteria optimization problem by a meta-heuristic algorithm may be useful for handling large-sized problems.

\section{Acknowledgements}

The authors would like to express their gratitude to the Higher Committee for Education Development (HCED) in Iraq for the financial support in this study. Also, the authors are thankful for constructive comments of the anonymous reviewers.

\section{References}

Ahmed, A. (2008). Marketing of halal meat in the United Kingdom. British Food Journal, 10(7), 655-670.

Altiparmak, F., Gen, M., Lin, L., \& Paksoy, T. (2006). A genetic algorithm approach for multiobjective optimization of supply chain Networks. Computers and Industrial Engineering, 51(1), 197-216.

Alumur, S.A., Nickel, S., Saldanha-da-Gama, F., \& Verter, V. (2012). Multi-period reverse logistics network design. European Journal of Operational Research, 220(1), 67-78.

ALmaraz, M. S. D. (2014). Multi-Objective Optimisation Of A Hydrogen Supply Chain. PhD Thesis, University of Toulouse.

Bonne, K., \& Verbeke, W. (2008). Religious values informing Halal meat production and the control and delivery of Halal credence quality. Agriculture and Human values, 25(1), 35-47.

Chang, Y.H. (2010). Adopting co-evolution and constraint-satisfaction concept on genetic algorithms to solve supply chain network design problems. Expert Syst Appl, 37(10), 6919-30.

Chankong, V., \& Haimes, Y. (1983). Multi-objective decision making theory and methodology. New York: Elsevier Science.

Deb, K. (2001). Multi-Objective Optimization using Evolutionary Algorithms. New York: John Wiley \& Sons. 
441 Ferrio, J., \& Wassick, J. (2008). Chemical supply chain network optimization. Comput $442 \quad$ Chem Eng, 32, 2481-504.

443 Gen, M., \& Cheng, R. (1997). Genetic Algorithms and Engineering Design. New York: 444 John Wiley \& Sons.

445 Hu, C.F., \& Li, S.Y. (2009). Two-phase interactive satisfying method of fuzzy multiple 446 objective optimization with linguistic preference. International Journal of Information 447 Technology \& Decision Making, 8(3), 427-443.

448 Jayaraman, V., \& Pirkul, H. (2001). Planning and coordination of production and distribution facilities for multiple commodities. European Journal of Operational Research, 133(2), 394-408.

Jayaraman, V., \& Ross, A. (2003). A simulated annealing methodology to distribution network design and management. European Journal of Operational Research, 144(3), $629-645$.

Lever, J., \& Miele, M. (2012). The growth of halal meat markets in Europe: An exploration of the supply side theory of religion. Journal of Rural Studies, 28(4), 528-537.

Li, F., Liu, T., Zhang, H., Cao, R., Ding, W., \& Fasano JP. (2008). Distribution center location for green supply chain. Proceedings of the IEEE International Conference on Service Operations, Logistics and Informatics, Beijing, 2951-2956.

Liu, S., \& Papageorgiou, L.G. (2014). Multiobjective optimisation of production, distribution and capacity planning of global supply chains in the process industry. Omega, 41, 369-382.

Max Shen, Z.J., \& Daskin, M.S. (2005). Trade-offs between customer service and cost in integrated supply chain design. Manufacturing \& Service Operations Management, 7(3), 188-207.

Miettinen, K. (1998). Nonlinear Multiobjective Optimization. Ed. $1^{\text {st }}$. Springer US: Springer Science+Business Media New York.

Mohammed, A. \& Wang. Q. (2015). Integrity of an RFID-enabled HMSC network. Proceedings of the Third International Conference on Digital Enterprise and Information Systems. China, 79-86.

Pandu, R.G. (2009). Multi-Objective Optimization: Techniques And Applications In Chemical Engineering (Advances in Process Systems Engineering). Singapore: World Scientific Publishing.

Peattie S., Peattie K. \& Jamal A. (2006). Influences on child nutrition: British Muslims. Pub. H. Nutri., 9/7a, 181-182.

Pourrousta, A., Dehbari, S., Tavakkoli-Moghadaam, R., \& Sadeghamalnik. M. (2012). A multi- objective particle swarm optimization for production-distribution planning in supply chain network. Manag Sci Lett, 2(2), 603-14.

Sabri, E.H., \& Beamon, B.M. (2000). A multi-objective approach to simultaneous strategic and operational planning in supply chain design. Omega, 28, 581-598. 
Sadjady, H., \& Davoudpour, H. (2012). Two-echelon, multi-commodity supply chain network design with mode selection, lead-times and inventory costs. Comput Oper Res, 39(7), 1345-54.

Schütz, P., Tomasgard, A., \& Ahmed, S. (2008). Supply chain design under uncertainty using sample average approximation and dual decomposition. European Journal of Operational Research, 199(2), 409-419.

Selim, H., Araz, C., \& Ozkarahan, I. (2008). Collaborative production-distribution planning in supply chain: a fuzzy goal programming approach. Transp Res Part E Logist Transp Rev, 44, 396-419.

Stoll, H.W. (1999). Product Design Methods and Practices. New York-Basel: Marcel dekker, Int.

Syam, S. S. (2002). A model and methodologies for the location problem with logistical components. Computers and Operations Research, 29(9), 1173-1193.

Syarif, A., Yun, Y., \& Gen, M. (2002). Study on multi-stage logistics chain network: a spanning tree-based genetic algorithm approach. Computers and Industrial Engineering, 43(1-2), 299-314.

Tuzkaya, U., \& Önüt, S. (2009). A holonic approach based integration methodology for transportation and warehousing functions of the supply network. Comput Ind Eng, 56(2), 708-23.

Yan, H., Yu, Z., \& Cheng, T. C. E. (2003). A strategic model for supply chain design with logical constraints: formulation and solution. Computers and Operations Research, 30(14), 2135-2155.

Charnes, A., Cooper, W.W., Ferguson, R. (1955). Optimal estimation of executive compensation by linear programming. Manag. Sci. 1, 138-151.

Colapinto, C., Jayaraman, R., Marsiglio, S. (2015). Multi-criteria decision analysis with goal programming in engineering, management and social sciences: a state-of the art review. Ann. Oper. Res., 1-34.

Chrysochou, P., Chryssochoids, G., \& Kehagia, O. (2009). Traceability information carriers. The technology backgrounds and consumers' perceptions of the technological solutions. Appetite, 53, 322-331.

Manos, B., \& Manikas, I. (2010). Traceability in the Greek fresh produce sector: drivers and constraints. British Food Journal, 112 (6), 640-652.

Zailani, S., Arrifin, Z., Abd Wahid, N., Othman, R. and Fernando, Y. (2010), "Halal traceability and halal tracking systems in strengthening halal food supply chains for food industry in Malaysia (a review)", Journal of Food Technology, Vol. 8 No. 3, pp. 74-81. 